Journal for ImmunoTherapy of Cancer

\title{
Therapeutic afucosylated monoclonal antibody and bispecific T-cell engagers for T-cell acute lymphoblastic leukemia
}

Daniele Caracciolo (D , , Caterina Riillo, ${ }^{1}$ Andrea Ballerini, ${ }^{2}$ Giuseppe Gaipa, ${ }^{3}$ Ludovic Lhermitte, ${ }^{4,5}$ Marco Rossi, ${ }^{1}$ Cirino Botta, ${ }^{6}$ Eugénie Duroyon, ${ }^{4,5}$ Katia Grillone, ${ }^{1}$ Maria Eugenia Gallo Cantafio, ${ }^{1}$ Chiara Buracchi, ${ }^{3}$ Greta Alampi, ${ }^{3}$ Alessandro Gulino, ${ }^{7}$ Beatrice Belmonte, ${ }^{7}$ Francesco Conforti, ${ }^{8}$ Gaetanina Golino, ${ }^{1}$ Giada Juli, ${ }^{1}$ Emanuela Altomare, ${ }^{1}$ Nicoletta Polerà,${ }^{1}$ Francesca Scionti, ${ }^{1}$ Mariamena Arbitrio, ${ }^{9}$ Michelangelo lannone, ${ }^{9}$ Massimo Martino, ${ }^{10}$ Pierpaolo Correale, ${ }^{11}$ Gabriella Talarico, ${ }^{12}$ Andrea Ghelli Luserna di Rorà, ${ }^{13}$ Anna Ferrari, ${ }^{13}$ Daniela Concolino, ${ }^{14}$ Simona Sestito, ${ }^{14}$ Licia Pensabene, ${ }^{14}$ Antonio Giordano, ${ }^{15}$ Markus Hildinger, ${ }^{16}$ Maria Teresa Di Martino, ${ }^{1}$ Giovanni Martinelli, ${ }^{13}$ Claudio Tripodo, ${ }^{7}$ Vahid Asnafi, ${ }^{4,5}$ Andrea Biondi, ${ }^{3}$ Pierosandro Tagliaferri, ${ }^{1}$ Pierfrancesco Tassone ${ }^{1,15}$

To cite: Caracciolo D, Riillo C, Ballerini A, et al. Therapeutic afucosylated monoclonal antibody and bispecific T-cell engagers for T-cell acute lymphoblastic leukemia. Journal for ImmunoTherapy of Cancer 2021;9:e002026. doi:10.1136/ jitc-2020-002026

- Prepublication history and additional material is published online only. To view please visit the journal online (http://dx.doi. org/10.1136/jitc-2020-002026).

DC and CR contributed equally. Accepted 17 January 2021

Check for updates

(C) Author(s) (or their employer(s)) 2021. Re-use permitted under CC BY-NC. No commercial re-use. See rights and permissions. Published by BMJ.

For numbered affiliations see end of article.

Correspondence to Professor Pierfrancesco Tassone; tassone@unicz.it

\section{ABSTRACT}

Background T-cell acute lymphoblastic leukemia (T-ALL) is an aggressive disease with a poor cure rate for relapsed/resistant patients. Due to the lack of T-cell restricted targetable antigens, effective immunetherapeutics are not presently available and the treatment of chemo-refractory T-ALL is still an unmet clinical need. To develop novel immune-therapy for T-ALL, we generated an afucosylated monoclonal antibody (mAb) (ahuUMG1) and two different bispecific T-cell engagers (BTCEs) against UMG1, a unique CD43-epitope highly and selectively expressed by T-ALL cells from pediatric and adult patients.

Methods UMG1 expression was assessed by immunohistochemistry $(\mathrm{HC})$ on a wide panel of normal tissue microarrays (TMAs), and by flow cytometry on healthy peripheral blood/bone marrow-derived cells, on 10 different T-ALL cell lines, and on 110 T-ALL primary patient-derived cells. CD43-UMG1 binding site was defined through a peptide microarray scanning. ahuUMG1 was generated by Genetic Glyco-Engineering technology from a novel humanized mAb directed against UMG1 (huUMG1). BTCEs were generated as IgG1-(scFv) ${ }_{2}$ constructs with bivalent $(2+2)$ or monovalent $(2+1)$ CD $3 \varepsilon$ arms. Antibody dependent cellular cytotoxicity (ADCC), antibody dependent cellular phagocytosis (ADCP) and redirected T-cell cytotoxicity assays were analysed by flow cytometry. In vivo antitumor activity of ahUMG1 and UMG1-BTCEs was investigated in NSG mice against subcutaneous and orthotopic xenografts of human T-ALL.

Results Among $110 \mathrm{~T}$-ALL patient-derived samples, 53 (48.1\%) stained positive (24\% of TI/TII, $82 \%$ of TIII and $42.8 \%$ of TIV). Importantly, no expression of UMG1-epitope was found in normal tissues/cells, excluding cortical thymocytes and a minority $(<5 \%)$ of peripheral blood T lymphocytes. ahUMG1 induced strong ADCC and ADCP on T-ALL cells in vitro, which translated in antitumor activity in vivo and significantly extended survival of treated mice.
Both UMG1-BTCEs demonstrated highly effective killing activity against T-ALL cells in vitro. We demonstrated that this effect was specifically exerted by engaged activated T cells. Moreover, UMG1-BTCEs effectively antagonized tumor growth at concentrations $>2$ log lower as compared with ahuUMG1, with significant mice survival advantage in different T-ALL models in vivo.

Conclusion Altogether our findings, including the safe UMG1-epitope expression profile, provide a framework for the clinical development of these innovative immunetherapeutics for this still orphan disease.

\section{BACKGROUND}

T-cell acute lymphoblastic leukemia (T-ALL) is an aggressive hematological malignancy derived from the abnormal proliferation of aberrant intra-thymic T-cell progenitors. ${ }^{12}$ Although T-ALL was historically associated with a substantially worse outcome as compared with B-cell ALL (B-ALL), intensive chemotherapy regimens have recently improved the prognosis of T-ALL patients. ${ }^{3-6}$ However, approximately $20 \%$ of pediatric and $50 \%$ of adult patients experience disease relapse/progression after first-line chemotherapy with a dismal outcome. ${ }^{78}$ In fact, in these patients, the only approved agent is nelarabine, which can provide temporary benefit in a minority of cases only $(30 \%),{ }^{9}$ while few eligible patients can benefit from allogeneic hematopoietic cell transplantation and induction of graft-versus-leukemia. ${ }^{1011}$

Unfortunately, while groundbreaking immunotherapeutic advancements have been achieved based on the targeting of 
B-cell antigens, such as CD19, CD20 and CD22, via chimeric antigen receptors (CAR-T) or bispecific T-cell engagers (BTCEs), and have dramatically empowered the treatment of relapsed/refractory B-ALL patients, the treatment landscape of relapsed/refractory T-ALL is still completely orphan and lacks immunotherapeutic options. Therefore, the development of innovative immunotherapeutics is urgently awaited.

We present here a promising experimental therapeutic approach based on the targeting of a unique epitope of CD43 (UMG1), which is highly expressed in corticalderived T-ALL cells. We developed an afucosylated form of the humanized mAb UMG1 (ahuUMG1) and two different BTCEs that, respectively, simultaneously bind UMG1-epitope on T-ALL cells and CD3e (by bivalent or monovalent arm) to induce cell-mediated killing of epitope-expressing leukemic cells. We performed an extensive analysis of the epitope expression on normal tissue/cells, and we investigated the in vitro and in vivo activity of these agents in different models of human T-ALL. The final aim of our study was the translational development of UMG1-based immune-therapeutics in the poor therapeutic landscape of T-ALL.

\section{MATERIAL AND METHODS}

For a more detailed description of the methods used, see online supplemental data.

\section{Cell lines}

Ke-37, PF-382, TALL-1, HPB-ALL, DND-41, MOLT-4, JURKAT, p12-ichikawa and ALL-SIL were purchased by DSMZ. CCRF-CEM cell lines was obtained by ATCC.

Ke-37, PF-382, TALL-1, DND-41, ALL-SIL, CCRF-CEM, MOLT-4, JURKAT, p12-ichikawa were cultured in RPMI1640 (Gibco, Life Technologies, Carlsbad, California, USA), supplemented with $10 \%$ fetal bovine serum (Lonza Group, Basel, Switzerland), $100 \mathrm{U} / \mathrm{mL}$ penicillin and 100 $\mathrm{mg} / \mathrm{mL}$ streptomycin (Gibco, Life Technologies), and maintained at $37^{\circ} \mathrm{C}$ in a $5 \% \mathrm{CO}_{2}$ atmosphere.

HPB-ALL cell line was cultured in RPMI-1640 supplemented with $20 \%$ fetal bovine serum.

\section{Patient samples}

BM o PB leukemia cells were collected from children with T-ALL enrolled in the AIEOP ALL 2009 protocol at the Pediatric Clinic of University of Milano Bicocca, San Gerardo Hospital and Hôpital Necker Enfants-Malades of Paris. Adult T-ALL samples were collected from IRST IRCCS of Meldola, in compliance with bioethical standards. Mononuclear cells were collected by Ficoll-Paque Plus (GE Healthcare) centrifugation and washed twice in culture medium (RPMI-1640 supplemented with 10\% Fetal Bovine Serum, FBS).

\section{Antibody humanization and chimerization}

Chain Heavy Chain Light (CHCL) chimeric antibody was generated by fusing the variable domain of the heavy chain and the variable domain of the light chain of the murine antibody to the corresponding human IgG1 constant domains. Humanized $\mathrm{H}(1-4) / \mathrm{L}(1-4)$ variants were generated by identifying murine complementary determinant regions that were grafted onto a human antibody framework. The IgG1 isotype was used for all humanized variants. Sixteen humanized antibody variants were constructed by replacing selected residues in the closest human germ line sequence of the framework regions, with the aim to preserve potentially structurally important residues of the murine counterpart. Additionally, eight hybrid CHL(1-4) and H(1-4) CL variants were generated. Recombinant genes were placed into the Evitria vector plasmid and transfected (with eviFect, Evitria) into CHO K1 cells. Cells were grown after transfection in animal-component free, serum-free medium (eviMake2, Evitria). Supernatant was harvested by centrifugation and subsequently sterile filtered ( $0.2 \mu \mathrm{m}$ filter). The antibodies were purified using MabSelect SuReresin.

Each of the humanized antibody has been screened for its affinity to the target (estimated by Mean Fluorescence Intensity, MFI) on two different cell lines (HPB-ALL and H9) as compared with chimeric and hybrid mAbs by flow cytometry. Each screening has been performed twice, for a total of four replicates. All tests have been performed under the same conditions: all mAbs were used at a final concentration of $1 \mu \mathrm{g} / \mathrm{mL}$; rituximab (Roche) has been used as IgG1 negative control; FITC Mouse Anti-Human IgG (BD Biosciences) has been used as secondary mAb.

\section{Generation of UMG1-BTCES}

Evitria cloned the UMG1 cDNAs into Evitria's vector system using conventional (non-PCR based) cloning techniques. The Evitria vector plasmids were gene synthesized. Plasmid DNA was prepared under low-endotoxin conditions based on anion exchange chromatography. DNA concentration was determined by measuring the absorption at a wavelength of $260 \mathrm{~nm}$. Correctness of the sequences was verified with Sanger sequencing (with up to two sequencing reactions per plasmid depending on the size of the cDNA). Evitria used suspension-adapted $\mathrm{CHO}$ K1 cells (originally received from ATCC and adapted to serum-free growth in suspension culture at Evitria) for production. The seed was grown in eviGrow medium, a chemically defined, animal-component free, serum-free medium. Cells were transfected with eviFect, and cells were grown after transfection in eviMake2. Supernatant was harvested by centrifugation and subsequent filtration (0.2 $\mu \mathrm{m}$ filter). The antibody was purified using MabSelect SuRe. Monovalent CD3 binding BTCE was generated using "Knobs-into-holes" technology.

\section{UMG1 expression analyses}

UMG1 expression on bone marrow, peripheral blood and T-ALL cell lines was evaluated by flow cytometry. Expression on normal tissue microarrays (TMAs) was evaluated by IHC. Detailed information can be found in online supplemental methods section. 


\section{In vitro antibody dependent cellular cytotoxicity assays}

Target cells were incubated with Peripheral Blood Mononuclear Cells (PBMCs) at effector to target cell ratios (E:T) 25:1 with rituximab $(50 \mu \mathrm{g} / \mathrm{mL})$, ahuUMG1 $(25-100 \mu \mathrm{g} / \mathrm{mL})$ antibodies or medium alone, $\mathrm{o} / \mathrm{n}$ at $37^{\circ} \mathrm{C}$ in RPMI $/ 10 \%$ fetal calf serum. Residual $\mathrm{T}$ lymphocytes CD8+ (CD45+, CD3+ and CD8+), T lymphocytes CD4+ (CD45+, CD3+ and CD4+), B lymphocytes (CD45+, CD3- and CD19+) and T-ALL cells (CD45 ${ }^{\mathrm{dim}}, \mathrm{CD} 3 \mathrm{dim} /-$ and $\mathrm{CD5}^{+}$) were analyzed by flow cytometry using a BD FACS CANTO II. The proportion of cells remaining was expressed as a percentage of control cultures incubated without the antibody. The following monoclonal antibodies were used for antigen detection: anti-CD3 PerCP Cy5.5 (Biolegend), anti-CD4 PE (Biolegend), anti-CD8 APC-H7 (Biolegend), anti-CD45 PO (Thermo Fisher Scientific), anti-CD19 PC7 (Beckman Coulter) and antiCD5 FITC (BD).

\section{Redirected T cell cytotoxicity assay}

T-ALL cell lines were labeled with Far Red (Invitrogen) viable marker, according to manufacturer instructions. Labeled cells were cocultured with PBMCs at different E:T ratio, in the presence of increasing concentrations of UMG1-BTCE or relative controls for $24-48$ hours at $37^{\circ} \mathrm{C}$ and $5 \% \mathrm{CO}_{2}$, and then stained with 7ADD (BD). Cytotoxicity was detected by flow cytometry (Attune NxT Flow cytometer, Thermo Fisher Scientific) as the percentage of 7AAD+/Far Red + cells. In the citotoxicity experiment with $\mathrm{T}$ cell depletion, immunomagnetic cell sorting using CD4 and CD8 microbeads (MACS Miltenyi Biotec) were used.

\section{In vivo studies}

Four to six weeks-old female NSG (NOD.Cg-PrkdcscidIl2rgtm1Wjl/SzJ) mice were purchased from Charles River Laboratories (Wilmington, Massachusetts, USA). During experiments, animals were regularly monitored and euthanized when tumors were $>2 \mathrm{~cm}^{3}$ or when signs of diseaserelated symptoms or graft-versus-host disease developed.

We performed two different experiments for in vivo activity evaluation of ahuUMG1 in T-ALL mouse models.

In the limited disease model, $10 \times 10^{6}$ HPB-ALL cells were subcutaneously injected. At day 7 mice were randomized into two groups (cohorts of five animals) of treatment ${ }^{1}$ : rituximab+NK92+interleukin (IL)- $2^{2}$; ahuUMG1+NK92+IL-2. The day after leukemic cells injection, antibodies were intraperitoneally injected at a dose of $15 \mathrm{mg} / \mathrm{kg}$ once a week, $15 \times 10^{6}$ NK92 cells were intravenous injected and $1800 \mathrm{UI} / \mathrm{mL}$ of IL-2 (Proleukin; Novartis Pharma, Nürnberg, Germany) was intraperitoneally administered. Treatment started the day after leukemic cells injection. Tumors were measured with calipers two times a week and tumor volume was calculated according to the formula (width2 $\times$ length) $/ 2=\mathrm{mm}^{3}$, where width was the shorter of the two measurements. Furthermore, in vivo evaluation of tumor volume was performed using IVIS LUMINA II Imaging System (Caliper Life
Sciences) after 15 min from tail vein injection of RediJect 2-DeoxyGlucosone (2-DG) (Perkin Elmer). In the disseminated model, CCRF-CEM-Luc+ were intravenous injected in NSG mice. Seven days after tumor cell injection, NSG mice were intravenous injected with human PBMC $\left(20 \times 10^{6}\right.$ cells $)$ and then randomized to receive rituximab (IgG1, control group) or ahuUMG1, at the dose of $15 \mathrm{mg} / \mathrm{kg}$ weekly. Intraperitoneally injection of mAbs was started at day 3 after PBMC engraftment. In vivo evaluation of tumor volume was performed using IVIS LUMINA II Imaging System.

For UMG1-BTCEs in vivo evaluation, CCRF-CEM-Luc+ were intravenous injected in NSG mice. After tumor engrafment, PBMC from healthy donors, as source of $\mathrm{T}$ cells, were engrafted. After 7 days, mice were weekly treated with intraperitoneally injection of UMG1-BTCE $(0.1 \mathrm{mg} / \mathrm{kg})$ or vehicle. In vivo evaluation of tumor volume was performed using IVIS LUMINA II Imaging System.

\section{Statistical analysis}

Each experiment was performed at least three times and values are reported as means $\pm \mathrm{SD}$. Comparisons between groups were made with Student's t-test, while statistical significance of differences among multiple groups was determined by GraphPad software (www.graphpad. com). Graphs were obtained using Graphpad Prism V.6.0. P value of less than 0.05 was accepted as statistically significant.

\section{RESULTS \\ Generation and characterization of humanized UMG1 mAb}

We generated a novel subclone, named UMG1 (ICLC Biobank, Genova, Italy, 2016) from the original hybridoma $^{12}$ by long-term subcloning procedures for clone selection and induction of activation-induced cytidine deaminase which may produce slight diversity in $\mathrm{mAb}$ reactivity and changes in scFv sequences among the original hybridoma and subclones. ${ }^{13} 14$ The mAb produced was differentially reactive on cells/tissues, as compared with original $\mathrm{mAb}$. On the sequence of murine UMG1, we developed 1 chimeric, 8 chimeric/humanized and 16 different humanized mAb variants, which underwent evaluation by flow cytometry for affinity on T-ALL cells. A clone based on H3 and L4 chains combination (data not shown) was selected for affinity and named humanized UMG1 mAb (huUMG1).

\section{huUMG1 recognizes a unique epitope on CD43 extracellular domain}

Although CD43 has been reported to be essential for the original parental clone murine mAb binding, ${ }^{15}{ }^{16}$ the specific binding site of huUMG1 was not defined so far. To this aim, a linear epitope mapping was performed through a peptide microarray scan. This assay revealed that the amino-acid sequence INEGSPLW, included from aa71 to aa78 of the extracellular domain of CD43 
is the binding peptide of huUMG1 (online supplemental figure 1A). To confirm this finding, the full-length coding sequence (CD43 \#1) and a cDNA that lacks the sequence encoding for the huUMG1 binding site (CD43 \#2) have been cloned into expression vectors and separately transfected into HEK293 cells, that do not express CD43. A strong binding of huUMG1 to the CD43 \#1 positive control was found, while no binding was observed for CD43 variant \#2 (online supplemental figure 1B). Moreover, to confirm that huUMG1 recognizes a unique epitope, a competitive binding assay among huUMG1 and commercially available CD43 antibodies (1G10, MEM-59, L10 clones) was performed. None of the tested anti-CD43 clones competes with huUMG1 in binding CCRF-CEM and HPB-ALL cells (online supplemental figure 1C).

Taken together, these findings indicate that huUMG1 recognizes a previously undescribed unique epitope of CD43.

\section{Reactivity of huUMG1}

To investigate the translational relevance of UMG1epitope, the pattern of huUMG1 reactivity on a wide panel of normal TMA was first evaluated according to FDA standards. A highly restricted pattern of reactivity was found. The only strong positive staining was detected on cortical lymphocyte progenitors within the thymus. No other normal tissues, including vital organs, were reactive. This pattern of expression of the UMG1-epitope is convincingly predictive of safety for clinical translation of immune-targeting agents (figure 1A).

In peripheral blood, huUMG1 reacted only with a very small subset of peripheral blood $\mathrm{T}$ lymphocytes $(<5 \%)$ from healthy children or adult donors, mostly represented by $\mathrm{CD} 4+\mathrm{T}$ cells, without identification of a specific subtype (figure 1B). No reactivity was found with granulocytes, monocytes, platelets and red blood cells (figure 1B). Importantly, no huUMG1 reactivity was observed on either pediatric lymphoid (CD19+) or non-lymphoid (CD19-) CD34+ stem/progenitor cells (figure 1C) and no toxicity was observed on healthy donor bone marrow CD34+ cell populations, as assessed by colony assay (online supplemental figure 2A).

Reactivity of huUMG1 was next evaluated by flow cytometry on a series of samples from hematological malignancies. Consistently with the huUMG1 reactivity on the thymus, a strong and selective positivity on primary T-ALL cells was observed, as compared with other hematological malignancies (figure 1D). Indeed, among 110 total T-ALL samples tested, $53(48.1 \%)$ were stained positive (cut-off $\geq 10 \%$ of positive blasts). Specifically, according to T-ALL European Group for the Immunological Classification of Leukemias (EGIL) classification, ${ }^{17} 24 \%$ of TI/TII, $82 \%$ of TIII and $42.8 \%$ of TIV were positive for huUMG1 with a varying degree of intensity of staining (figure 1E). The highest intensity was reached in EGILTIII samples, where 20 out of 39 samples $(51.2 \%)$ showed $>55 \%$ of huUMG1 positive blasts. Furthermore, among tested early T-lineage progenitor leukemias (EGIL-TI subgroup), $33.3 \%$ was huUMG1 positive, thus suggesting a potential role of UMG1 in the most aggressive type of T-ALL (online supplemental table).

Consistently with data on pediatric/adult primary leukemic cells, strong reactivity towards T-ALLcell lines was observed. Indeed, among T-ALL cell lines, 7/10 clearly expressed the target, while one showed minor expression and two lines no expression. In particular, UMG1-epitope was expressed in a range between 125,400 and 1858 antigen molecules on Ke-37 and p-12 Ichikawa cells, respectively (figure 1F,G).

Taken together these findings indicate that the UMG1epitope is a promising immune-therapeutic target for T-ALL patients. At this aim, we developed two species of innovative tools: (i) an afucosylated humanized mAb UMG1 (ahuUMG1) and (ii) two different BTCEs, in the aim to empower the therapeutic targeting of UMG1epitope on leukemic cells.

\section{Afucosylated huUMG1 binding activity on T-ALL cells}

It is well known that afucosylation of IgG1 mAbs significantly improves Antibody Dependent Cellular Cytotoxicity (ADCC) if compared with the fucosylated form of the same mAb. The afucosylated form of huUMG1 (ahuUMG1) was generated by the Genetic GlycoEngineering/ADCC (GlymaxX) technology.

Dose titration experiments were performed to define the apparent constant of dissociation (Kd) with ahuUMG1 on Ke-37 cell line. Average apparent Kd was estimated at $0.15 \mu \mathrm{g} / \mathrm{mL}$, while the saturation of binding was reached at concentrations of about $1.00 \mu \mathrm{g} / \mathrm{mL}$ (figure 2A). Taking into account that downregulation of epitopes is frequently observed on antibody binding, with potential limitation of therapeutic efficacy, the UMG1epitope stability was evaluated. Substantial stability of the MFI values during the whole analysis was observed, indicating that neither modulation of the epitope nor shedding of the $\mathrm{Ab} / \mathrm{Ag}$ complex occurs on huUMG1 binding (figure 2B). Next, to investigate whether the expression stability was associated to the mAb internalization, HPBALL cell line was exposed to increasing concentrations of ahuUMG1 for up to 72 hours. Again, no changes in MFI were observed (data not shown). This result was also confirmed by immunofluorescence analysis, which showed plasma membrane colocalization of ahuUMG1 and wheat germ agglutinin, a marker commonly used to label plasma membrane glycoproteins, after 48 hours from staining with $1 \mu \mathrm{g} / \mathrm{mL}$ of ahuUMG1 (figure 2C).

These results indicate that the epitope bound by $\mathrm{mAb}$ huUMG1 has stable expression on the membrane of target cells and that the binding of the mAb does not affect this property.

\section{ahuUMG1 induce ADCC and antibody dependent cellular phagocytosis on T-ALL cells in vitro}

Based on these findings, the therapeutic activity of ahuUMG1 was investigated in vitro. HPB-ALL, CCRF-CEM and Ke-37 cell lines were exposed to ahuUMG1 25-50 

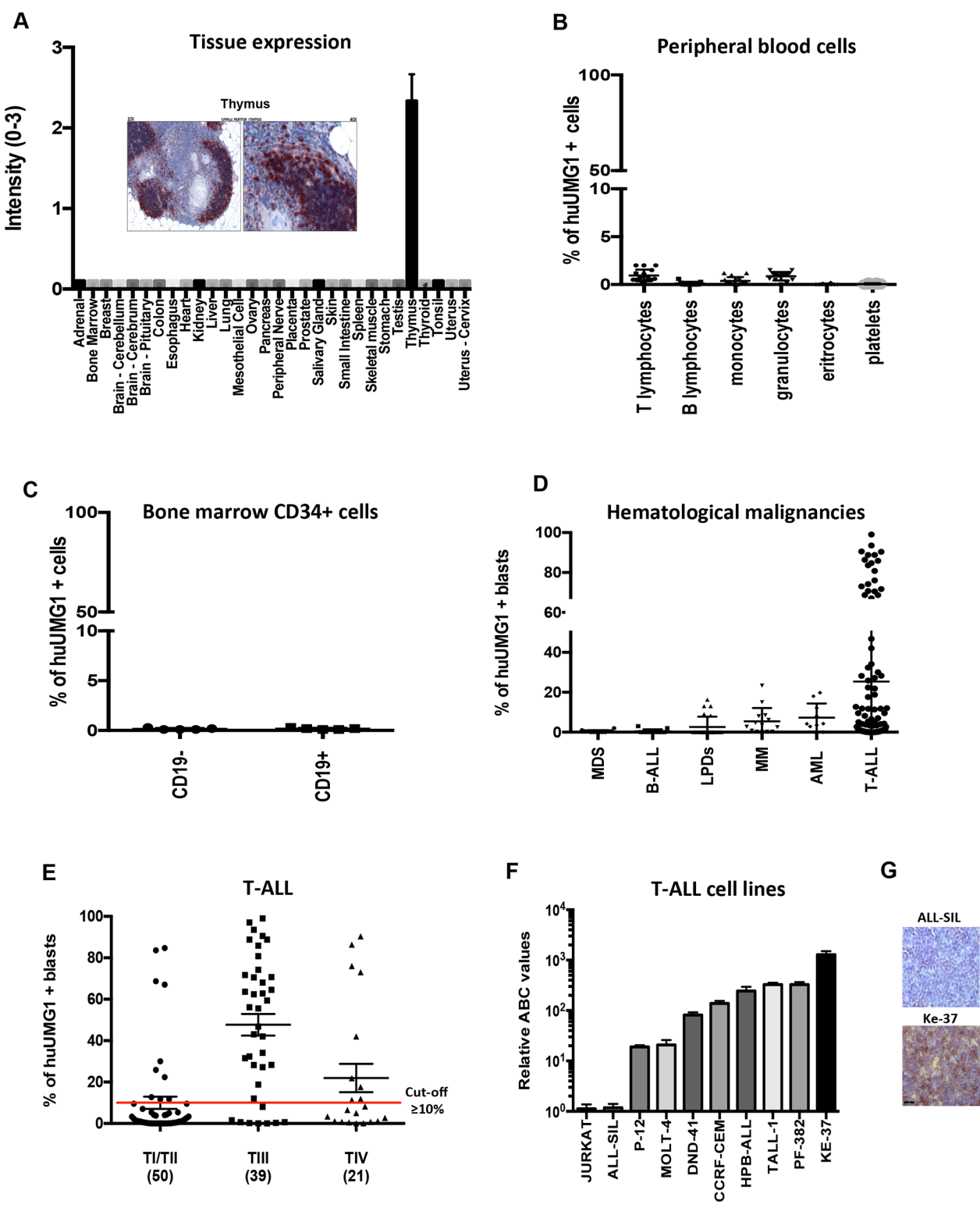

Figure 1 UMG1 expression on human healthy and leukemic cells. (A) Immunohistochemical staining intensity (score 0-3) of huUMG1 on normal tissues. Strong immunohistochemical staining of huUMG1 on human thymic cortical is shown. (B) UMG1 expression on human healthy donor peripheral blood cells. (C) UMG1 expression on CD19+/- CD34+ human healthy bone marrow cells. (D) UMG1 expression on a panel of hematological malignancies. (E) Focus of UMG1 expression on T-ALL blasts from 110 patients according to EGIL classification: TI/TII (50 cases), TIII (39 cases), TIV (21). ${ }^{21}$ (F) Relative fluorescence quantitation of UMG1 as evaluated by Fluorescence-activated cell sorting (FACS) analysis. (G) Immunohistochemistry analysis of UMG1 in a UMG1-positive cell line (Ke-37) as compared with a UMG1-negative one (ALL-SIL). EGIL, European Group for the Immunological Classification of Leukemias; FACS, Fluorescence-activated cell sorting; huUMG1, humanized monoclonal antibody directed against UMG1; T-ALL, T-cell acute lymphoblastic leukemia.

$\mu \mathrm{g} / \mathrm{mL}$ and cell survival and proliferation were evaluated. Cell viability was not affected after 72 hours of treatment (online supplemental figure 3A) indicating that targeting of UMG1-epitope does not trigger direct cytotoxicity. Additionally, ahuUMG1 does not induce complement dependent cytotoxicity (data not shown).

Based on these data, ADCC against T-ALL cells was evaluated after ahuUMG1 exposure. UMG1-positive T-ALL cell lines HPB-ALL, CCRF-CEM and Ke-37 were cocultured with human healthy donors-derived PBMCs at different effector/target ratios in the presence of increasing concentrations of ahuUMG1 for 24 hours. Viable cells were detected by flow cytometry as 7AAD-/ Far Red+ cells. Importantly, ahuUMG1 demonstrated in vitro ADCG against UMG1-positive cells (HPB-ALL, CCRF-CEM and Ke-37) (figure 2D). Moreover, the antileukemic activity of ahuUMG1 was evaluated on primary cells by coculturing healthy donor's derived PBMCs with patient-derived malignant cells exposed to escalating doses of ahuUMG1. A significant induction of ADCC was observed in UMG1+ blasts only (figure 2E). Importantly, in the same primary samples, cytotoxic effects 

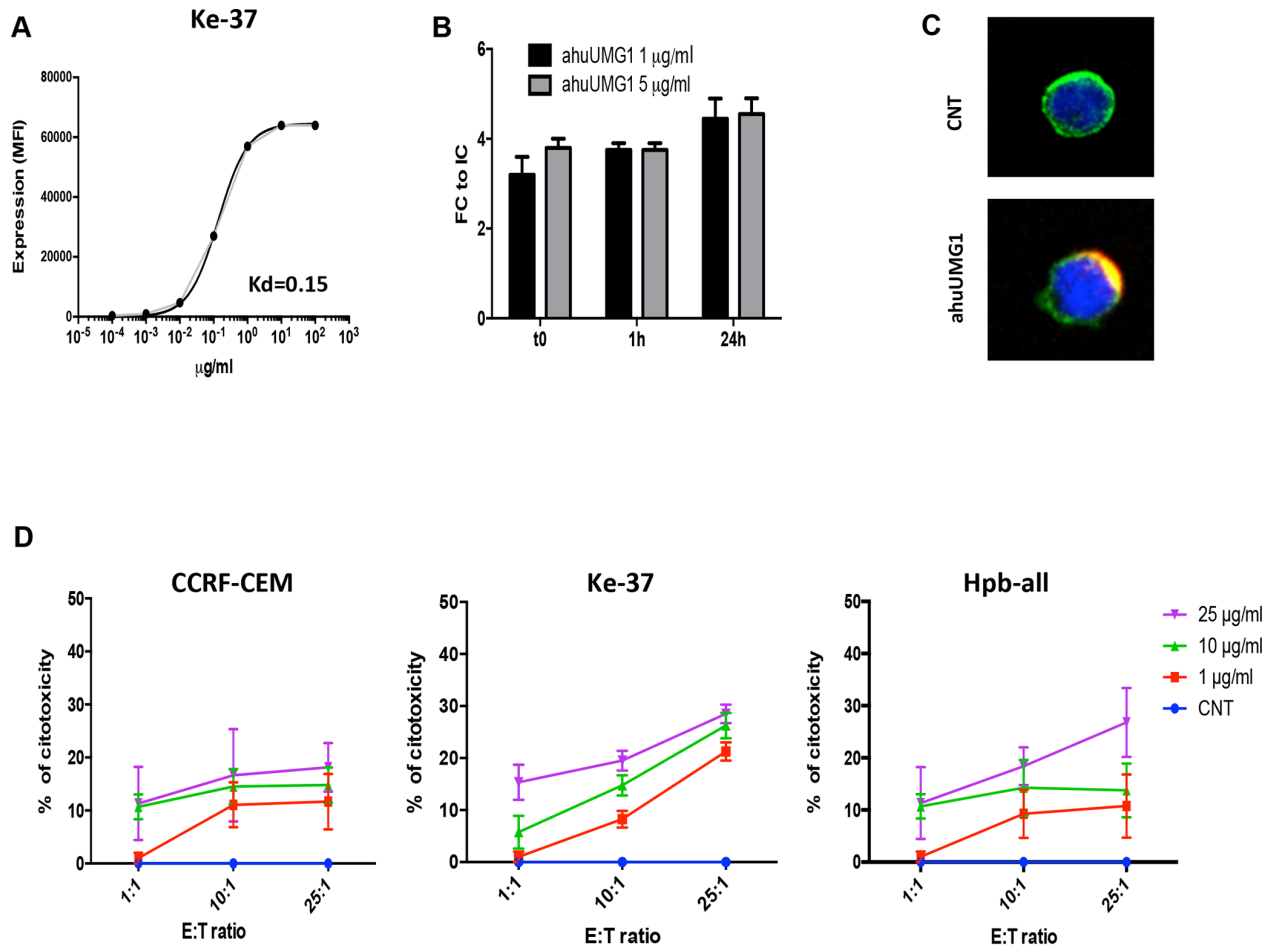

E

$\mathbf{F}$
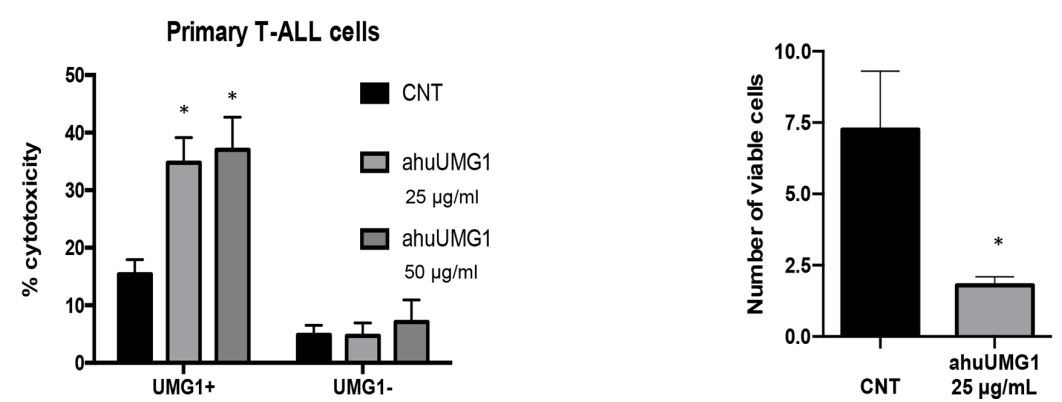

Figure 2 ahuUMG1 in vitro activity characterization. (A) Average apparent Kd evaluated by flow cytometry on Ke-37 cell line. (B) UMG1epitope shedding evaluation on HPB-ALL cell line treated with $1 \mu \mathrm{g} / \mathrm{mL}$ and $5 \mu \mathrm{g} / \mathrm{mL}$ of Dy634-labeled huUMG1. MFI fold change (FC) for each time point (t0, 1 hour, 24 hours) as compared with isotype control (IC) as evaluated by FACS analysis, is shown. (C) Immunofluorescence analysis of epitope internalization was evaluated on Ke-37 cells. The images show membrane colocalization of huUMG1 (red) and wheat germ agglutinin (green) 48 hours after treatment. (D) Percentage of cytotoxicity in T-ALL huUMG1 positive CCRF-CEM, HPB-ALL and Ke-37, cocultured in the presence of PBMCs and ahuUMG1 $25 \mu \mathrm{g} / \mathrm{mL}$ or lgG1 $25 \mu \mathrm{g} / \mathrm{mL}$ at 25:1 E:T ratio for 12 hours. (E) Percentage of cytotoxicity in UMG1-positive (nine cases) as compared with UMG1-negative (six cases) T-ALL primary blasts treated with ahuUMG1 25 and $50 \mu \mathrm{g} / \mathrm{mL}$ or lgG1 $50 \mu \mathrm{g} / \mathrm{mL}$ and cocultured with PBMCs at 25:1 E:T ratio for 12 hours. (F) Percentage of viable cells (HPB-ALL) treated for 7 days with ahuUMG1 $25 \mu \mathrm{g} / \mathrm{mL}$ and cocultured with PBMCs (E:T=500:1) as compared with control. * $\mathrm{p}<0.05$. ahuUMG1, afucosylated form of the humanized monoclonal antibody UMG1; huUMG1, humanized UMG1 monoclonal antibody; CNT, control; FACS, Fluorescenceactivated cell sorting; MFI, Mean Fluorescence Intensity; PMBC, Peripheral Blood Mononuclear Cells; T-ALL, T-cell acute lymphoblastic leukemia.

were observed neither on residual normal CD4+ lymphocytes nor in CD19+ B lymphocytes (online supplemental figure 3B). To recapitulate in vitro the clinical context of minimal residual disease (MRD) positive patients, coculture of healthy donors PBMCs and HPB-ALL cell line, at a very high effector/target ratio (E:T of 500:1) for 7 days, was next performed. Treatment with ahuUMG1 significantly reduced the number of residual tumor cells, strongly suggesting a potential clinical application of ahuUMG1 for purging the MRD (figure 2F), without affecting normal CD8, CD4 and monocytes populations.

Importantly, antileukemic activity induced by ahuUMG1 treatment was associated to a dose-related downregulation of CD16 (figure 3A) and increase of CD107a (figure 3B) and interferon (IFN)- $\gamma$ expression (figure 3C) on natural killer (NK) cells. Then, the potential role of the monocyte/macrophages compartment in the antitumor activity of ahuUMG1 was evaluated. 


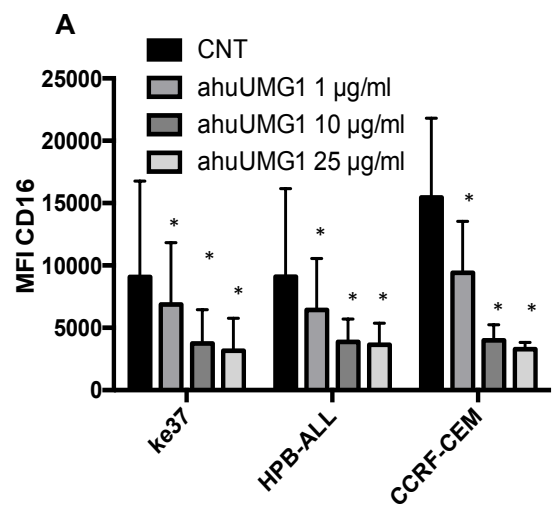

B

C

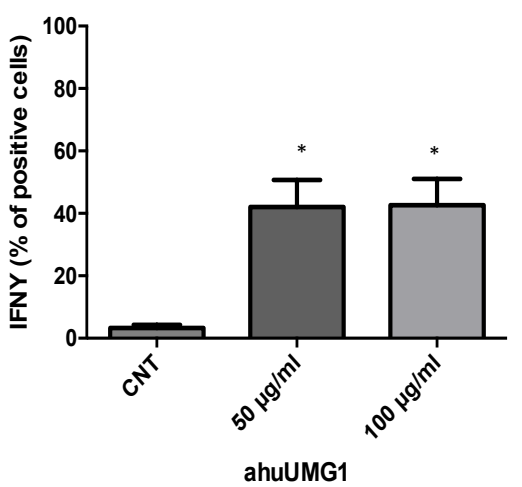

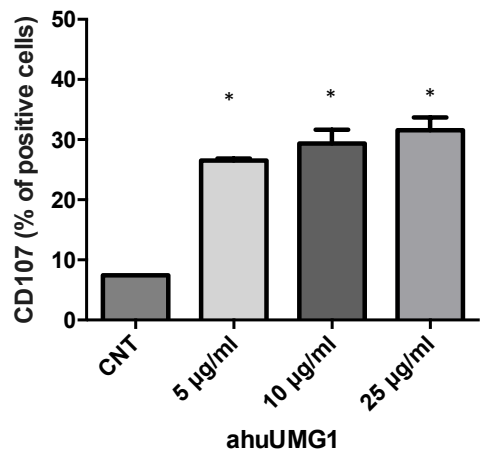

D

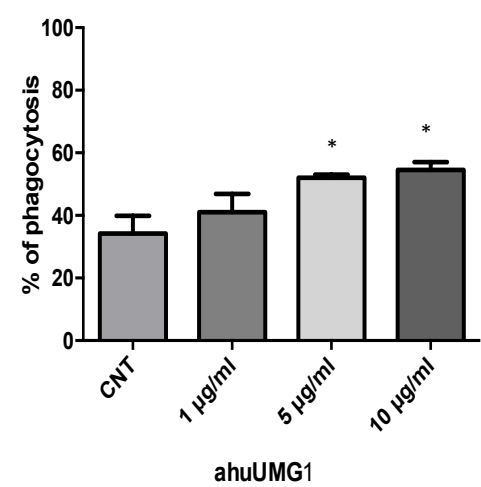

E

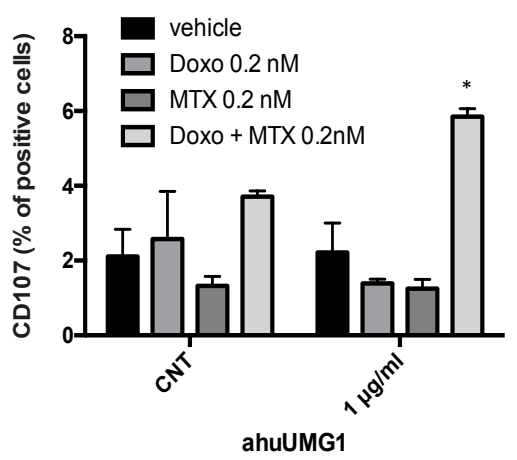

Figure 3 Mechanism of antitumor action of ahuUMG1. CD16 MFI downregulation (A), interferon (IFN)- $\gamma$ production (B) and $\%$ of CD107a positivity (C) in effector cells (PBMCs) cocultured with CCRF-CEM, after ahuUMG1 treatment as compared to CNT. (D) ahuUMG1 induction of antibody dependent cellular phagocytosis on CCRF-CEM cell line cocultured with human healthy macrophages in 5:1 E:T ratio for 4 hours. (E) Cytotoxic effects induced by ahuUMG1 and cytotoxic drug combination on HPB-ALL cells. " $\mathrm{p}<0.05$. ahuUMG1, afucosylated form of the humanized monoclonal antibody UMG1; CNT, control; DOXO, doxorubicin; MFI, Mean Fluorescence Intensity; MTX, methotrexate; PMBC, Peripheral Blood Mononuclear Cells.

Consistently with mAb-induced CD16-downregulation on NK cells, overnight stimulation with ahuUMG1 in the presence of effector and target cells induced a decrease in CD16 expression on monocytes indicating their activation. ahuUMG1 led to monocyte-dependent antibody dependent cellular phagocytosis (ADCP) in CCRF-CEM and Ke-37 cell lines plated with monocyte-derived macrophages (at E:T of 4:1) and exposed to increasing concentrations of the mAb (figure 3D).

Finally, to evaluate the ahuUMG1 efficacy in combination with conventional chemotherapeutic agents, HPB-ALL cells were first exposed to methotrexate (MTX) and doxorubicin (DOXO), alone or in combination. Notably, sublethal dose of these drugs induced a rapid and significant increase of UMG1-epitope expression. Consistently with expression data, NK activation (evaluated by CD107a degranulation) was higher after combined treatment with ahuUMG1 and MTX and/or DOXO (figure 3E), which actually led to significant enhancement of ADCC against T-ALL cells. These findings appear of relevance for induction of effective ahuUMG1-dependent immune-response by combinatory approaches. 
A

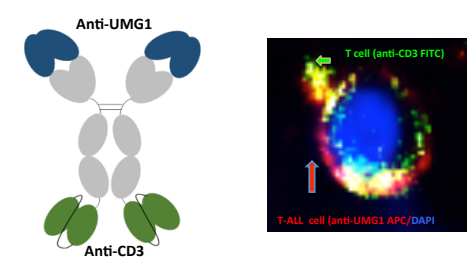

B

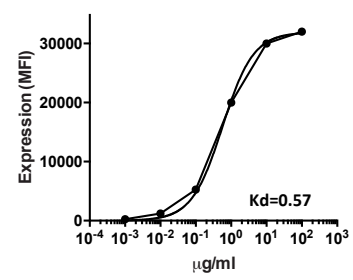

C
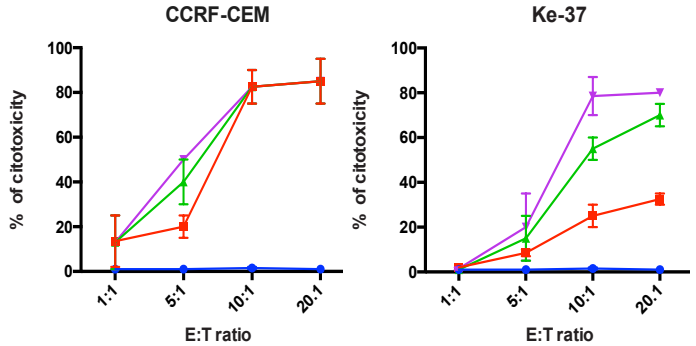

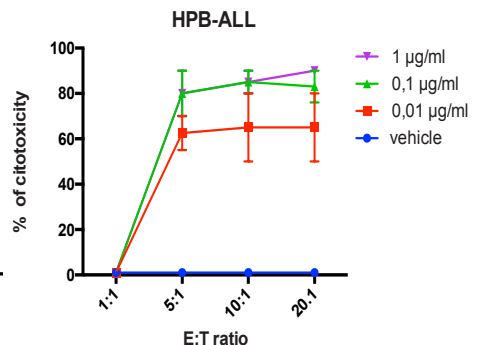

D

E
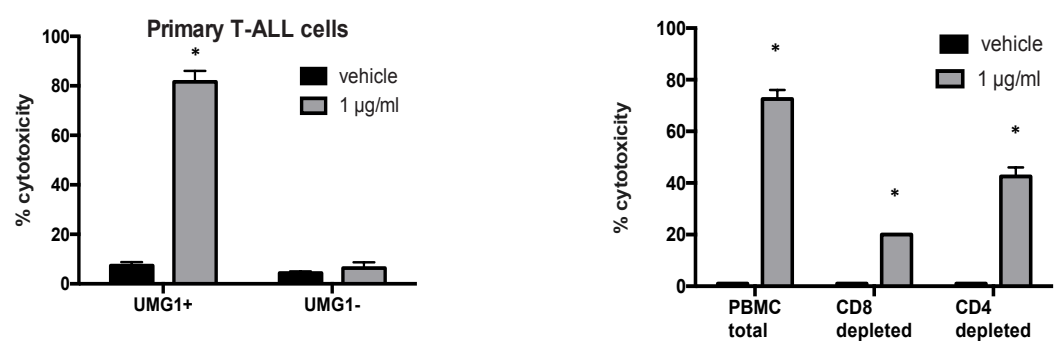

Figure 4 bUMG1-BTCE redirects T lymphocytes to kill T-ALL cells in vitro (A) left panel: schematic representation of the bUMG1-BTCE structure. Right panel: coupling of a CD3+ T cell on Ke-37 cells by bUMG1 BTCE as assessed by immunofluorescence microscopy. T cells are stained with anti-CD3 (FITC), CCRF-CEM cells with anti-UMG1-APC and DAPI counterstaining; (B) equilibrium dissociation constants (KD) for bUMG1 BTCE binding to UMG1 on Ke-37 cells; (C) redirected T-cell-mediated lysis monitored by viable target cell Far Red labeled T-ALL cell lines (CCRF-CEM, Ke-37, HPB-ALL) cocultured with PBMCs at different E:T ratio and treated with increasing bUMG1 BTCE concentrations for 48 hours. (D) Redirected T-cellmediated lysis of UMG1-positive as compared with UMG1-T-ALL primary blasts cocultured for 48 hours with PBMCs at 10:1 E:T ratio and treated with $1 \mu \mathrm{g} / \mathrm{mL}$ of bUMG1 BTCE. (E) CCRF-CEM cells incubated with full or CD8 or CD4-cell-depleted PBMCs as effector cells and treated with $1 \mu \mathrm{g} / \mathrm{mL}$ at 10:1 E:T ratio. ${ }^{*} \mathrm{p}<0.05$. bUMG1, bivalent UMG1; MFI, Mean Fluorescence Intensity; PMBC, Peripheral Blood Mononuclear Cells; MFI T-ALL, T-cell acute lymphoblastic leukemia.

\section{Bivalent UMG1-BTCE redirects T lymphocytes to kill UMG1- positive T-ALL cells}

To further empower the therapeutic value of ahuUMG1 in vitro and in vivo, we generated a bispecific IgG1-(scFv) construct $(2+2)$, that also bivalently binds the $\varepsilon$ subunit of CD3 (figure 4A,B). Bivalent UMG1-BTCE (bUMG1BTCE) activity was first evaluated by assessing its ability to mediate redirected cytolysis by using healthy donors PBMCs as effector cells and several T-ALL cell lines as target cells. In vitro cytotoxicity assays were performed on UMG1-positive target cells Ke-37, CCRF-CEM and HPB-ALL as well as on UMG1-negative ALL-SIL cells, cocultured with effectors at different $\mathrm{E}: \mathrm{T}$ ratio, in the presence of increasing concentrations of bUMG1-BTCE. 
Importantly, bUMG1-BTCE demonstrated in vitro cytotoxicity in T-ALL UMG1-positive cells with an EC50 of $0.01 \mu \mathrm{g} / \mathrm{mL}$ in CCRF-CEM and HPB-ALL and $0.1 \mu \mathrm{g} / \mathrm{mL}$ in Ke-37 cells at E:T ratio of 10:1 (figure 4C). Conversely, as formal proof of target specificity, no cytotoxic effects were observed after BTCE treatment of ALL-SIL (online supplemental figure 4A). Moreover, T-ALL cell viability was not affected after 72 hours treatment in the absence of effector cells (Supplemental figure 4B), indicating that bUMG1-BTCE does not trigger direct cytotoxic effects. Activity of bUMG1-BTCE toward primary T-ALL primary cells was next tested. bUMG1-BTCE induced cytotoxic activity only in UMG1+ samples, wherein blasts were 90\% lysed (figure 4D). In particular, to demonstrate $\mathrm{T}$ cell-mediated bUMG1-BTCE cytotoxicity, T-ALL cell lines were cocultured with total human PBMCs or immunomagnetic T-CD8 or T-CD4 cell-depleted PBMCs. Importantly, while minimal cytotoxic activity was observed in T-CD8 depleted samples compared with total PBMCs, a residual T-ALL cell lysis was found in T-CD4 depleted samples, thus demonstrating that bUMG1-BTCE cytotoxicity on T-ALL cells is mainly mediated by cytotoxic CD8 T-lymphocytes (figure 4E). Finally, functional effects induced by bUMG1-BTCE treatment on PBMCs cocultured with T-ALL cell lines were evaluated. Importantly, upregulation of early and late T-cell activation markers, such as CD25 and CD69, was observed (figure 5A), without affecting viability of healthy donors' PBMCs (figure 5B). Additionally, bUMG1-BTCE induced release of Tumor Necrosis Factor- $\alpha$ (TNF- $\alpha)$ and Interferon- $\gamma($ IFN- $\gamma)$ and (figure 5C,D). Consistent with their prominent cytotoxic function, T-CD8 lymphocytes were positive to CD107a activation marker (figure 5E).

\section{Antitumor activity of ahuUMG1 and bUMG1-BTCE in vivo}

Based on in vitro findings, we aimed to validate the therapeutic effectiveness of ahuUMG1 and bUMG1 BTCE in different murine models of human T-ALL.

In the first model, HPB-ALL cells were injected subcutaneously in NSG mice and animals were then randomized to receive intraperitoneal rituximab (IgG1, control group) or ahuUMG1, both treated at a dose of $15 \mathrm{mg} / \mathrm{kg}$ weekly. We found that ahuUMG1 strongly reduced tumor growth as compared with control mice (figure 6A). Interestingly, 60 days after cell engraftment, IHC analysis of tumors retrieved from treated animals showed high NK cell infiltration in ahuUMG1 treated mice, as compared with control group (not shown).

In the second model, mice were systemically (intravenous) injected with CCRF-CEM-Luc+ cells to recapitulate the disseminated feature of the disease. Seven days after tumor cell injection, NSG mice were intravenous injected with human PBMCs and then randomized to receive rituximab (IgG1, control group) or ahuUMG1, at the dose of $15 \mathrm{mg} / \mathrm{kg}$ weekly 3 days after PBMCs engraftment. As compared with rituximab, ahuUMG1 induced a significant inhibition of tumor growth that translated in prolonged survival of treated mice of almost 1 month (figure 6B).

Taken together these findings demonstrate a significant antitumor activity of ahuUMG1 against T-ALL xenografts in vivo.

Finally, to investigate in vivo bUMG1-BTCE activity, CCRF-CEM-Luc+ were engrafted in NSG mice. After tumor development, PBMCs from healthy donors, as source of $\mathrm{T}$ cells, were engrafted. After 7 days, mice were weekly intraperitoneally treated with bUMG1-BTCE $(0.1$ $\mathrm{mg} / \mathrm{kg}$ ) or vehicle. Of note, significantly reduced tumor growth and prolonged survival were observed in bUMG1BTCE treated mice, as compared with control mice (figure 6C).

Taken together, these results indicate that bUMG1BTCE is a highly effective and promising tool to be investigated in non-human primates for setting the better conditions for a First-in-Human study in patients with T-ALL.

\section{Monovalent CD3\& binding empowers UMG1-BTCE activity}

Several studies have shown that the valency for CD3e binding may affect the efficacy of the BTCE molecules. Indeed, by limiting the crosslinking of CD3 molecules on the surface of T cells, CD3e monovalent binding may reduce T-cell unspecific activation and exhaustion. On these premises, a UMG1-BTCE with monovalent CD3e arm (mUMG1-BTCE) was generated and the binding of this new construct to UMG1-epitope was assessed (online supplemental figure 5A). To characterize this novel agent format $(2+1)$, effector cells were cocultured with T-ALL cell lines (CCRF-CEM and Ke-37) at 10:1 E:T ratio in the presence of CD3 $\varepsilon$ bivalent or monovalent UMG1-BTCEs $(0.1 \mu \mathrm{g} / \mathrm{mL})$ for 24 hours. Consistently, as compared with bivalent BTCE, the monovalent construct resulted in lower PD1, TIM3 and TIGIT expression thus confirming a reduction of $\mathrm{T}$ cell exhaustion (figure $7 \mathrm{~A}$ ). Interestingly, a stronger redirected cytotoxicity on T-ALL cells (figure 7B, online supplemental figure 5B) and higher proliferation of effector cells (online supplemental figure C) were observed after treatment with the CD3 $\varepsilon$ monovalent construct, as compared with the bivalent one. Importantly, as for bUMG1-BTCE, in the absence of effector cells, T-ALL cell viability was not affected by mUMG1BTCE (data not shown).

To investigate the translational relevance of our in vitro findings, in vivo activity of mUMG1-BTCE on the disseminated mouse model of T-ALL was evaluated. Importantly, a significant survival advantage and reduction of tumor growth (figure 7C,D), together with a lower expression of $\mathrm{T}$ cell exhaustion markers (online supplemental figure 5D), were observed in mUMG1-BTCE treated mice, as compared with control mice.

Overall, these findings suggest that a $2+1$ format of UMG1-BTCE must be preferred to a $2+2$ construct, in a clinical translation aimed at an immune-therapeutic approach to T-ALL patients. 

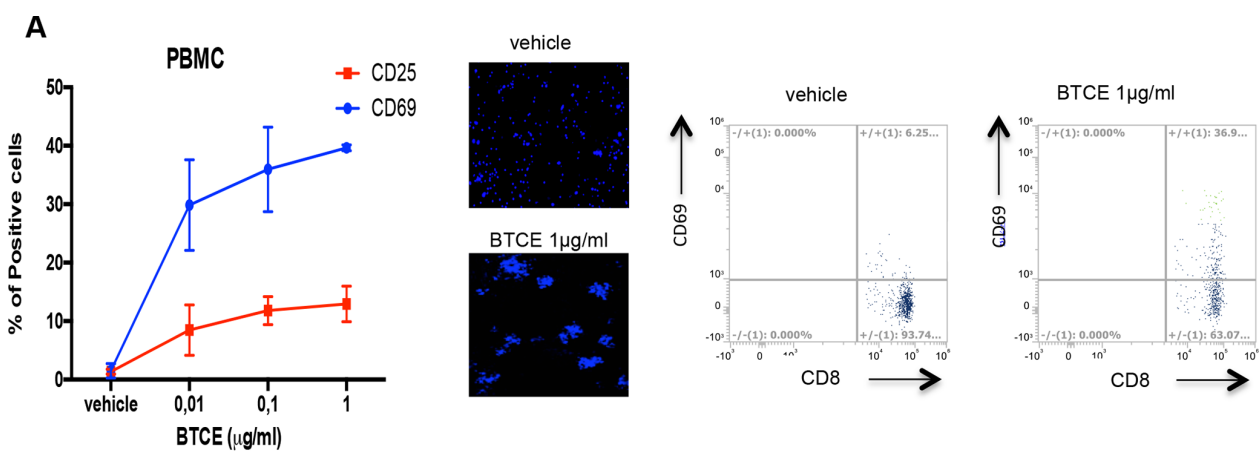

B

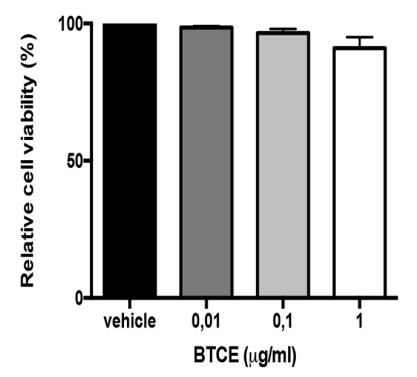

D

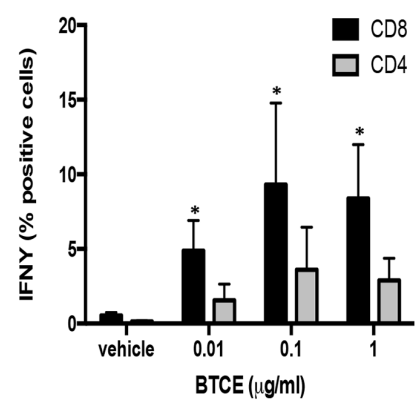

C

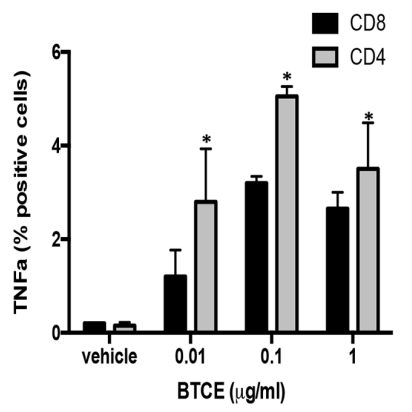

E

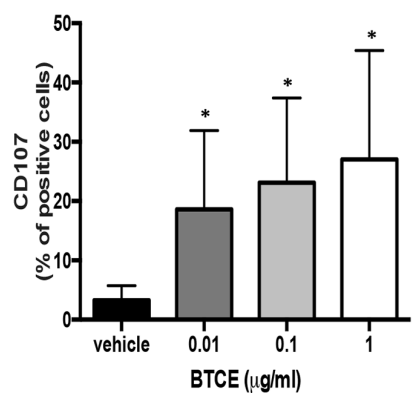

Figure 5 bUMG1-BTCE activates T lymphocytes against T-ALL cells. (A) CCRF-CEM cells were cocultured for 24 hours with PBMC (E:T=10:1) in the presence of bUMG1 BTCE or vehicle. Left: percentages of CD69+ and CD25+ PBMCs. Middle: morphological phenotype (rosetting) of DAPI-stained lymphocytes after BTCE-mediated activation. Right: representatives FACS traces showing percentage of CD69 positivity on effector CD8 T cells after treatment with $1 \mu \mathrm{g} / \mathrm{mL}$ of UMG1-BTCE. (B) PBMCs were cocultured with Far Red labeled CCRF-CEM at E:T ratio of 10:1 and then treated with increasing bUMG1-BTCE concentrations for 48 hours. Cell viability of effector cells was evaluated as the percentage of Far Red negative cells not stained by 7-AAD. (C-D) Percentages of TNF- $\alpha$ (C) and interferon (IFN)- $\gamma$ (D) CD4+ and CD8+ cells and percentage of CD107a. (E) CD8+ cells, after 24 hours of incubation of CCRF-CEM cells cocultured with PBMC (E:T=10:1) in presence of bUMG1 BTCE or vehicle. ${ }^{*} \mathrm{p}<0.05$. bUMG1, bivalent UMG1; T-ALL, T-cell acute lymphoblastic leukemia.

\section{DISCUSSION}

At present, the cure of refractory/relapsed T-ALL is still an unmet need. While immunotherapy-based strategies greatly improved the treatment of B-ALL, no immunotherapeutic options are available for the treatment of T-ALL. Here, we report the generation, characterization and preclinical validation of novel immune agents for the targeting of the UMG1 epitope, whose pattern of expression does not overlap with other CD43-epitopes. We found that huUMG1 binds to a relevant proportion of primary T-ALL samples form pediatric and adult patient, thus providing proof-of-concept for an innovative therapeutic approach against T-ALL.
We generated an ahuUMG1, a bivalent and a monovalent UMG1-BTCE in the aim to investigate the potential antitumor effectiveness of redirecting immune cells to UMG1epitope expressing T-ALL cells. AhuUMG1 strongly induced significant ADCC and ADCP against T-ALL cells in vitro. Interestingly, we found that conventional cytotoxic agents, such as MTX or DOX, enhanced the epitope expression and its targeting by the ahuUMG1 on T-ALL blasts, increasing NK-mediated cell death and, therefore, providing the rationale for combinatory therapies. Moreover, ahuUMG1 was highly active against T-ALL xenografts in NSG mouse models, which recapitulate different clinical scenarios, within 
A

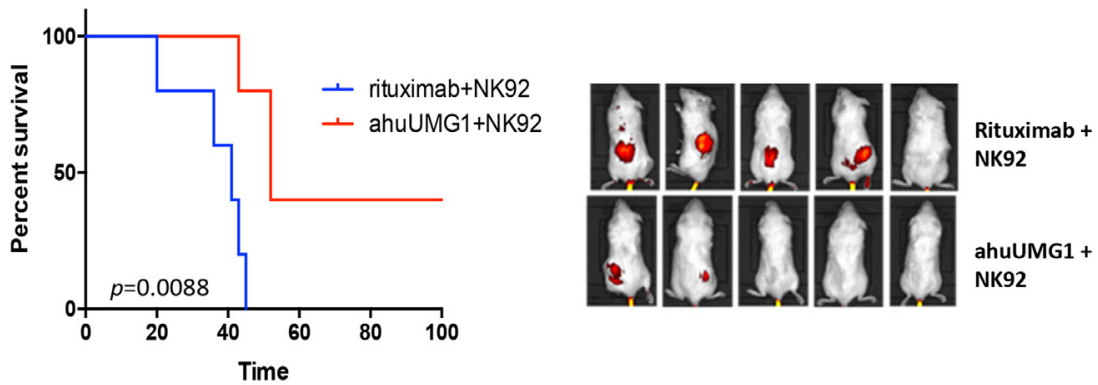

B

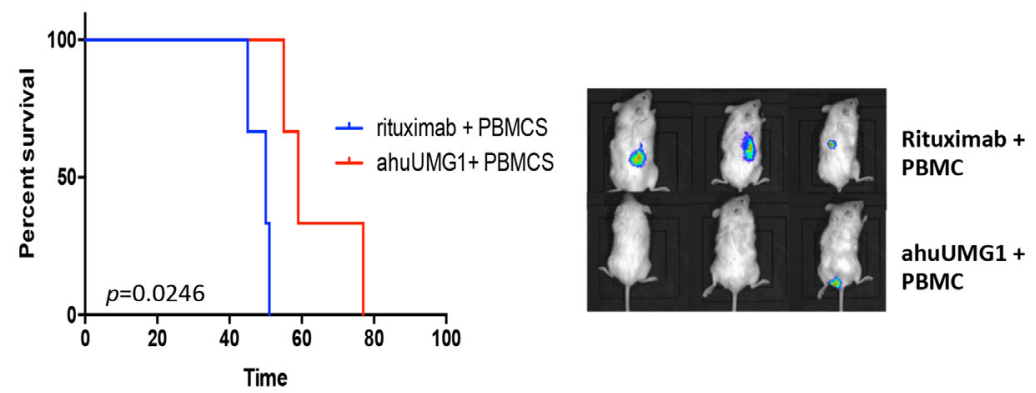

C

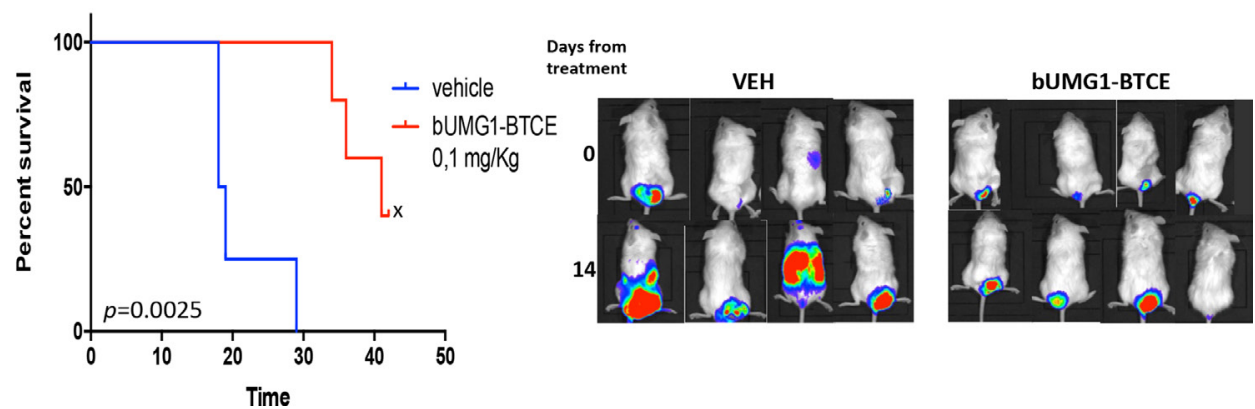

Figure 6 ahuUMG1 and UMG1-BTCE exert antileukemic activity in in vivo models of T-ALL. (A, B) In vivo activity of ahuUMG1 $(15 \mathrm{mg} / \mathrm{kg})$ after once a week intraperitoneal injection compared with rituximab at equimolar dose. (A) $5 \times 10^{6} \mathrm{HPB}-\mathrm{ALL}$ cells were injected subcutaneously in NSG mice. The day after leukemic cells injection, antibodies were intraperitoneal injected at a dose of $15 \mathrm{mg} / \mathrm{kg}$ once a week, $15 \times 10^{6} \mathrm{NK92}$ cells were intravenous injected and $1800 \mathrm{UI} / \mathrm{mL}$ of interleukin 2 was intraperitoneal administered. The treatment started the day after leukemic cells injection. Survival curves (Kaplan-Meier) (left) and IVIS imaging (right) in a subcutaneous model of disease are shown. (B) NSG mice were systemically (intravenous) injected with $1 \times 10^{6}$ CCRFCEM-Luc+. Seven days after tumor cell injection, animals were intravenous injected with human PBMCs $\left(20 \times 10^{6}\right.$ cells). Three days after PBMCs engraftment, mice were randomized to receive intraperitoneal rituximab (IgG1, control group) or ahuUMG1 at the dose of $15 \mathrm{mg} / \mathrm{kg}$ weekly. Survival curves (Kaplan-Meier) (left) and IVIS imaging (right) are shown. (C) CCRF-CEM-Luc+ were intravenous injected in NSG mice. After tumor engraftment, PBMCs from healthy donors were engrafted. After 7 days, mice were weekly treated with intraperitoneal injection of bUMG1-BTCE $(0.1 \mathrm{mg} / \mathrm{kg})$ or vehicle. Left: survival curves (KaplanMeier) of each group (log-rank test, $p<0.05$ ). " $X$ " indicates that observation was stopped due to COVID-19 emergency. Right: IVIS imaging showing bioluminescence in bUMG1-BTCE treated mice as compared with control group. ahuUMG1, afucosylated form of the humanized monoclonal antibody UMG1; PMBC, Peripheral Blood Mononuclear Cells; T-ALL, T-cell acute lymphoblastic leukemia; bUMG1-BTCE, bivalent-UMG1- bispecific T cell engager.

an achievable therapeutic window. ${ }^{18}$ We next developed the bivalent bUMG1-BTCE (UMG1-CD3e, 2+2) to redirect T lymphocytes towards UMG1-expressing T-ALL cells. bUMG1BTCE showed strong antileukemic activity within a doserange approximately 150 times lower than ahuUMG1. As expected, bUMG1-BTCE actually produced a concentrationdependent activation of $\mathrm{T}$ cells, release of inflammatory cytokines and induction of $\mathrm{T}$ cell proliferation, leading to
T-ALL cells lysis in a time-dependent, dose-dependent and E:T ratio-dependent manner. To avoid unspecific T-cell activation deriving by bivalent binding to $\mathrm{CD} 3 \varepsilon$, a monovalent UMG1-BTCE (UMG1-CD3 $\varepsilon, 2+1$ ) construct was finally generated. Interestingly, while mUMG1-BTCE induced lower T-cell exhaustion, it indeed resulted in stronger antitumor activity, as compared with bUMG1-BTCE. Consistently with in vitro data, both UMG1-BTCEs exerted a significant tumor growth 
A
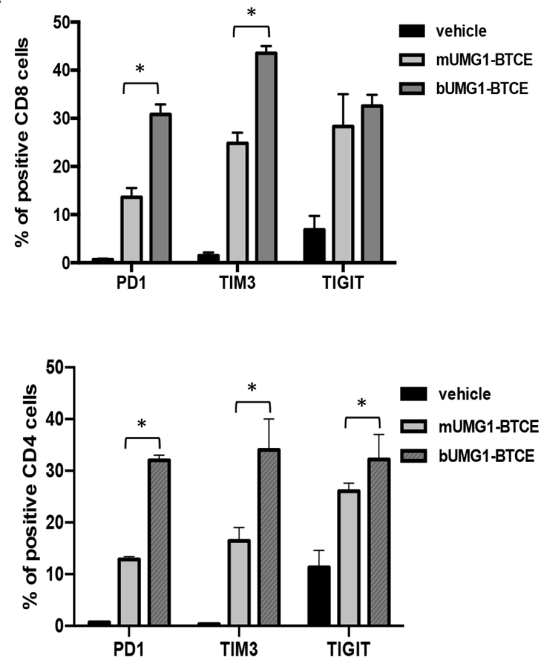

B

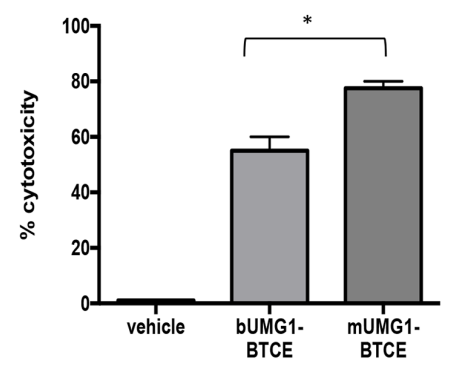

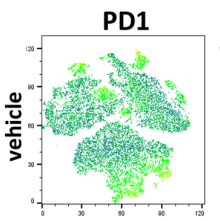
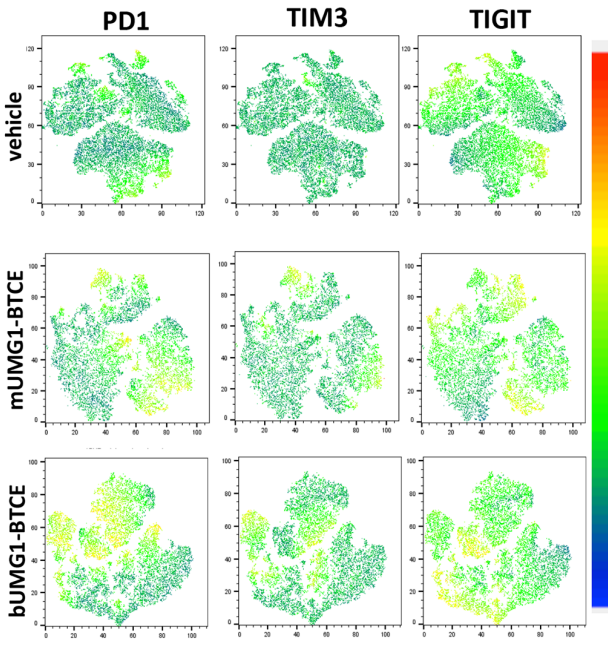

C

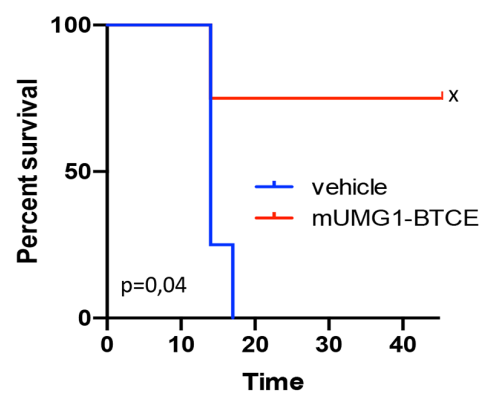

D

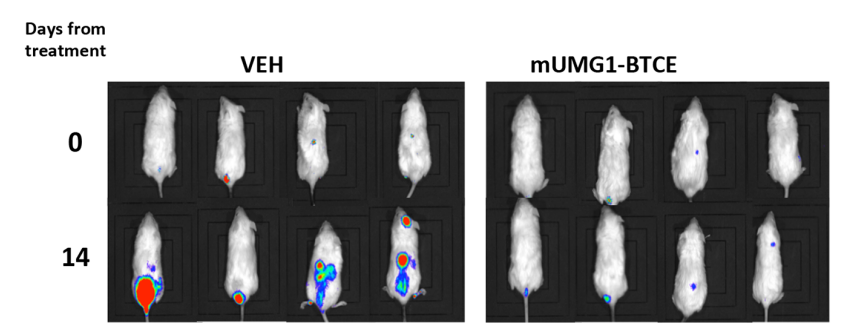

Figure 7 CD3 $\varepsilon$ monovalent binding reduces T cell exhaustion empowering antileukemic activity of UMG1-BTCE. (A-C) CCRFCEM cells were cocultured for 24 hours with PBMC (E:T=10:1) in the presence of monovalent or bivalent UMG1 BTCE (0.1 $\mu$ g/ $\mathrm{mL}$ ): (A) FACS analysis (tSNE) of exhaustion markers expression on effector cells. (B) Redirected cytotoxicity assay on CCRFCEM cells. (C) In vivo activity of monovalent UMG1-BTCE $(0.1 \mathrm{mg} / \mathrm{kg})$ after weekly intraperitoneal injection. Survival curves (Kaplan-Meier) of each group (log-rank test, $p<0.05)$ are shown. " $X$ " the observation was discontinued after 40 days and animals were sacrificed. (D) IVIS imaging showing bioluminescence in mUMG1-BTCE treated mice as compared with control group. ${ }^{*} \mathrm{p}<0.05$. FACS, Fluorescence-activated cell sorting; PMBC, Peripheral Blood Mononuclear Cells

inhibitory activity in an orthotopic model of systemic/circulating advanced disease, in a range of concentrations similar to the doses used for blinatumomab, the first BTCE approved for clinical use against B neoplasms. ${ }^{19}$

We think that our results could be of specific relevance in the light of the growing interest for a mAb-based therapy against T-cell tumors. However, to date, the development of such therapeutics for T-ALL has been hampered by the shared expression of many targetable antigens among normal and neoplastic cells, whose targeting is predicted to produce impairment of cell-mediated immunity and consequent severe immunosuppression. In this context, the
anti-CD52 mAb alemtuzumab showed promising preclinical activity against adult T-cell leukemia. ${ }^{20}$ However, since CD52 is also expressed on normal T-cells, the treatment led to immunosuppression and increased risk of opportunistic infections. In one report, the anti-CD3 Muromonab led to a dramatic, although transient response in a patient with refractory T-ALL. However, this $\mathrm{mAb}$ also increased TCR-signaling resulting in life-threatening cytokine-release syndrome, increased risk of opportunistic infections and

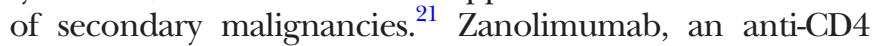
mAb, showed an overall response of $34.2 \%$ in cutaneous T-cell lymphoma patients and $22.2 \%$ patients with Sezary cell 
leukemia. However, these effects occurred together with a dose-dependent and profound CD4+ lymphocytopenia and consequent immunosuppression. ${ }^{22}$ Although expressed by majority of T-ALL, CD7 is also expressed by bone-marrow stem cells, progenitor cells committed to lymphocytic differentiation at prethymic stages, by cortical and medullary thymocytes, and up to mature stage by circulating $\mathrm{T}$ cells and NK cells. Targeting CD7 could therefore result in heavy and prolonged cell-mediated immunosuppression. Similarly, the wide expression of CD5 in hematopoietic compartments suggest that its targeting in T-ALL might also affect cellmediated immune-surveillance.

On these premises, the discovery of novel T-ALL selective antigens is an unmet need for the treatment of this aggressive disease. Anti-CD96 mAb (TH-111) showed only limited reactivity with blood and bone marrow nucleated cells but stained a major (78.3\%) subset of T-ALL (ALL), representing a potential tool for clinical translation but still awaiting for translational development. ${ }^{23}$

In this scenario, the advantage of here presented UMG1-epitope is the lack of expression by hematopoietic stem cells as well as by normal tissues, excluding cortical thymocytes and a minority of $\mathrm{T}$ lymphocytes. We therefore do not expect immunodeficiency associated with the targeting of UMG1-epitope expressing thymocytes for the residual role in adult life, while in young patients, emigrating $\mathrm{T}$ cells are generated very early in the embryonic life and persist for decades, thus making unlike impairment of T-cell repertoire in adult life. ${ }^{24}$

The heavily glycosylated protein CD43 exists in many variants ${ }^{25}$ that are differentially expressed by T-cell during ontogenesis and activation, or with aberrant expression in cancer cells. ${ }^{26} 27$ This explains why, even if the UMG1epitope is expressed on CD43 core protein structure, its pattern of expression significantly differs from other epitopes recognized by available anti-CD43 mAbs. ${ }^{28-30}$ Recently, other anti-CD43 antibodies have been described for potential use in the treatment of acute myeloid leukemia (AML). ${ }^{31}{ }^{32}$ For instance, a novel $\mathrm{mAb}$ and a BTCE against a different glycoform of CD43 expressed on AML have been recently investigated. ${ }^{33}$ However, due to its wide expression on cells of the hematopoietic system and other tissues, CD43 cannot provide the best target option for immunotherapeutic approaches, whereas the CD43-expressing UMG1-epitope is of major value for its highly restricted expression.

To the best of our knowledge, our findings describe the first BTCE targeting T-ALL with a potential very low risk of T-cell immunosuppression. Importantly, BTCEs do not require ex vivo manipulation and are off-the-shelf therapeutics, with easier use in daily practice over CAR-T.

In conclusion, we demonstrated that ahuUMG1 and UMG1-BTCEs could be safe and effective T-ALL specific therapeutics to be explored in a First-in-Human clinical trial and to be developed in the front-line as well as maintenance treatment, such as blinatumomab for the control of MRD. Our preclinical findings allow also the design of alternative immune-UMG1-based therapeutic strategies, such as CARs or bispecific NK engagers, ${ }^{35}$ therefore expanding the framework for a novel immunotherapeutic strategy for this still incurable orphan disease.

\section{Author affiliations}

${ }^{1}$ Department of Experimental and Clinical Medicine, Magna Græcia University of Catanzaro, Catanzaro, Italy

${ }^{2}$ BiovelocITA srl, Milano, Italy

${ }^{3}$ Centro Ricerca M. Tettamanti, Clinica Pediatrica Università Milano-Bicocca,

Ospedale San Gerardo, Monza, Italy

${ }^{4}$ Université de Paris, Institut Necker-Enfants Malades, Institut National de Recherche Médicale U1151, Paris, France

${ }^{5}$ Laboratory of Onco-Hematology, Assistance Publique-Hôpitaux de Paris, Hôpital Necker Enfants-Malades, Paris, France

${ }^{6}$ Hematology Unit, Annunziata Hospital, Cosenza, Italy

${ }^{7}$ Tumor Immunology Unit, Department of Health Sciences, Human Pathology

Section, University of Palermo, Palermo, Italy

${ }^{8}$ Pathology Unit, Annunziata Hospital, Cosenza, Italy

${ }^{9}$ IRIB-CNR, Catanzaro, Italy

${ }^{10}$ Stem Cell Transplant Program, Clinical Section, Department of Hemato-Oncology and Radiotherapy, Grande 0spedale Metropolitano Bianchi-Melacrino-Morelli, Reggio Calabria, Italy

${ }^{11}$ Medical Oncology Unit, "Bianchi-Melacrino-Morelli" Grand Metropolitan Hospital, Reggio Calabria, Italy

${ }^{12}$ Immunotransfusion Service Unit, Pugliese-Ciaccio Hospital, Catanzaro, Italy

${ }^{13}$ Istituto Scientifico Romagnolo per lo Studio e la Cura dei Tumori (IRST) IRCCS,

Meldola, Italy

${ }^{14}$ Department of Medical and Surgical Sciences, Pediatric Unit, University "Magna

Graecia" of Catanzaro, Catanzaro, Italy

${ }^{15}$ Sbarro Institute for Cancer Research and Molecular Medicine, Center for Biotechnology, College of Science and Technology, Temple University, Philadelphia, Pennsylvania, USA

${ }^{16}$ Evitria, Zurich, Switzerland

\section{Twitter Emanuela Altomare @ea}

Acknowledgements We thank Dr Ivana Criniti for her helpful support in study coordination and assistance.

Contributors DC, CR, ABa, CB, KG, MEGC, CBu, GG, GJ, EA, NP and FS, performed experiments and/or analyzed the data. GG, LL, MR, ED, GA, MA, AGLDR, AF, MM, MTDM, PC and GT provided biological samples and analyzed the data. PT developed the $\mathrm{mAb}$. MH developed bioconstructs generation technology. AG, BB, FC and $\mathrm{Ml}$ performed IHC analysis. ABa, GG, LL, MR, CB, PC, DCo, SS, LP, AG, MH, MTDM, $\mathrm{GM}, \mathrm{CT}, \mathrm{VA}$ and $\mathrm{AB}$ provided critical evaluation of experimental data and of the manuscript. DC, CR, ABa, PTagliaferri and PTassone conceived the study and wrote the manuscript. PTagliaferri and PTassone supervised the study.

Funding This work has been supported by BiovelocITA and partially by the Italian Association for Cancer Research (AIRC)/CARICAL Multi Unit Regional No.16695, 2015/18 (PI: PT); AIRC IG 2017 and AIRC 5x1000, №. 21147 (PI: AB); Fondazione Alessandro Maria Zancan ONLUS “GrandeAle ONLUS”; Fondazione M. Tettamanti De Marchi; TRANSCAN-2 Fondazione Regionale per la Ricerca Biomedica (to AB).

Competing interests None declared.

\section{Patient consent for publication Not required.}

Ethics approval All in vivo experiments were approved by the Institutional Ethical Committee of the Magna Graecia University and all the procedures were performed according to the Institutional Animal Care-approved protocols and guidelines.

Provenance and peer review Not commissioned; externally peer reviewed.

Data availability statement All data relevant to the study are included in the article or uploaded as supplementary information.

Supplemental material This content has been supplied by the author(s). It has not been vetted by BMJ Publishing Group Limited (BMJ) and may not have been peer-reviewed. Any opinions or recommendations discussed are solely those of the author(s) and are not endorsed by BMJ. BMJ disclaims all liability and responsibility arising from any reliance placed on the content. Where the content includes any translated material, BMJ does not warrant the accuracy and reliability of the translations (including but not limited to local regulations, clinical guidelines, terminology, drug names and drug dosages), and is not responsible 
for any error and/or omissions arising from translation and adaptation or otherwise.

Open access This is an open access article distributed in accordance with the Creative Commons Attribution Non Commercial (CC BY-NC 4.0) license, which permits others to distribute, remix, adapt, build upon this work non-commercially, and license their derivative works on different terms, provided the original work is properly cited, appropriate credit is given, any changes made indicated, and the use is non-commercial. See http://creativecommons.org/licenses/by-nc/4.0/.

\section{ORCID iD}

Daniele Caracciolo http://orcid.org/0000-0001-7870-7565

\section{REFERENCES}

1 Ballesteros-Arias L, Silva JG, Paiva RA, et al. T cell acute lymphoblastic leukemia as a consequence of thymus autonomy. $J$ Immunol 2019;202:1137-44.

2 Van Vlierberghe P, Ferrando A. The molecular basis of T cell acute lymphoblastic leukemia. J Clin Invest 2012;122:3398-406.

3 Winter SS, Dunsmore KP, Devidas M, et al. Improved survival for children and young adults with T-lineage acute lymphoblastic leukemia: results from the children's Oncology Group AALL0434 methotrexate randomization. J Clin Oncol 2018;36:2926-34.

4 Schrappe M, Valsecchi MG, Bartram CR, et al. Late MRD response determines relapse risk overall and in subsets of childhood T-cell all: results of the AIEOP-BFM-ALL 2000 study. Blood 2011;118:2077-84.

5 Annino L, Vegna ML, Camera A, et al. Treatment of adult acute lymphoblastic leukemia (all): long-term follow-up of the GIMEMA all 0288 randomized study. Blood 2002;99:863-71.

6 Hoelzer D, Gökbuget N. T-Cell lymphoblastic lymphoma and T-cell acute lymphoblastic leukemia: a separate entity? Clin Lymphoma Myeloma 2009;9 Suppl 3:S214-21.

7 Peirs S, Frismantas V, Matthijssens F, et al. Targeting BET proteins improves the therapeutic efficacy of Bcl-2 inhibition in T-cell acute lymphoblastic leukemia. Leukemia 2017;31:2037-47.

8 Cheng Z, Yi Y, Xie S, et al. The effect of the JAK2 inhibitor TG101209 against T cell acute lymphoblastic leukemia (T-ALL) is mediated by inhibition of JAK-STAT signaling and activation of the crosstalk between apoptosis and autophagy signaling. Oncotarget 2017;8:106753-63

9 DeAngelo DJ, Yu D, Johnson JL, et al. Nelarabine induces complete remissions in adults with relapsed or refractory T-lineage acute lymphoblastic leukemia or lymphoblastic lymphoma: cancer and leukemia group B study 19801. Blood 2007;109:5136-42.

10 Bakr M, Rasheed W, Mohamed SY, et al. Allogeneic hematopoietic stem cell transplantation in adolescent and adult patients with high-risk T cell acute lymphoblastic leukemia. Biol Blood Marrow Transplant 2012;18:1897-904.

11 Brammer JE, Saliba RM, Jorgensen JL, et al. Multi-Center analysis of the effect of T-cell acute lymphoblastic leukemia subtype and minimal residual disease on allogeneic stem cell transplantation outcomes. Bone Marrow Transplant 2017;52:20-7.

12 Tassone $\mathrm{P}$, Bond $\mathrm{H}$, Bonelli $\mathrm{P}$, et al. UN1, a murine monoclonal antibody recognizing a novel human thymic antigen. Tissue Antigens 1994;44:73-82.

13 Xin $\mathrm{H}$, Cutler JE. Hybridoma passage in vitro may result in reduced ability of antimannan antibody to protect against disseminated candidiasis. Infect Immun 2006;74:4310-21.

14 Bradbury ARM, Trinklein ND, Thie $\mathrm{H}$, et al. When monoclonal antibodies are not monospecific: hybridomas frequently express additional functional variable regions. MAbs 2018;10:539-46.
15 Cecco L, Bond HM, Bonelli P, et al. Purification and characterization of a human sialoglycoprotein antigen expressed in immature thymocytes and fetal tissues. Tissue Antigens 1998;51:528-35.

16 de Laurentiis A, Gaspari M, Palmieri C, et al. Mass spectrometrybased identification of the tumor antigen UN1 as the transmembrane CD43 sialoglycoprotein. Mol Cell Proteomics 2011;10:M111.007898-7898.

17 Bene MC, Castoldi G, Knapp W, et al. Proposals for the immunological classification of acute leukemias. European group for the immunological characterization of leukemias (EGIL). Leukemia 1995;9:1783-6.

18 Manches O, Lui G, Chaperot L, et al. In vitro mechanisms of action of rituximab on primary non-Hodgkin lymphomas. Blood 2003;101:949-54.

19 Gökbuget N, Dombret H, Bonifacio M, et al. Blinatumomab for minimal residual disease in adults with $\mathrm{B}$-cell precursor acute lymphoblastic leukemia. Blood 2018;131:1522-31.

20 Zhang Z, Zhang M, Goldman CK, et al. Effective therapy for a murine model of adult T-cell leukemia with the humanized anti-CD52 monoclonal antibody, Campath-1H. Cancer Res 2003;63:6453-7.

21 Alcantara M, Tesio M, June $\mathrm{CH}$, et al. Car T-cells for T-cell malignancies: challenges in distinguishing between therapeutic, normal, and neoplastic T-cells. Leukemia 2018;32:2307-15.

$22 \mathrm{Kim}$ YH, Duvic M, Obitz E, et al. Clinical efficacy of zanolimumab (HuMax-CD4): two phase 2 studies in refractory cutaneous T-cell lymphoma. Blood 2007;109:4655-62.

23 Gramatzki M, Ludwig WD, Burger R, et al. Antibodies TC-12 ("unique") and TH-111 (CD96) characterize T-cell acute lymphoblastic leukemia and a subgroup of acute myeloid leukemia. Exp Hematol 1998;26:1209-14.

24 Haynes BF, Hale LP, Weinhold KJ, et al. Analysis of the adult thymus in reconstitution of T lymphocytes in HIV-1 infection. J Clin Invest 1999;103:921.

25 Tuccillo FM, de Laurentiis A, Palmieri C, et al. Aberrant glycosylation as biomarker for cancer: focus on CD43. Biomed Res Int 2014;2014:1-13.

26 Perkey E, Maurice De Sousa D, Carrington L, et al. GCNT1-Mediated O-Glycosylation of the Sialomucin CD43 Is a Sensitive Indicator of Notch Signaling in Activated T Cells. J Immunol 2020;204:1674-88.

27 Modak M, Majdic O, Cejka P, et al. Engagement of distinct epitopes on CD43 induces different co-stimulatory pathways in human T cells. Immunology 2016;149:280-96.

28 Alvarado M, Klassen C, Cerny J, et al. MEM-59 monoclonal antibody detects a CD43 epitope involved in lymphocyte activation. Eur $J$ Immunol 1995;25:1051-5.

29 Nong YH, Remold-O'Donnell E, LeBien TW, et al. A monoclonal antibody to sialophorin (CD43) induces homotypic adhesion and activation of human monocytes. J Exp Med 1989;170:259-67.

30 Mambole A, Baruch D, Nusbaum P, et al. The cleavage of neutrophil leukosialin (CD43) by cathepsin G releases its extracellular domain and triggers its intramembrane proteolysis by presenilin/gammasecretase. J Biol Chem 2008;283:23627-35.

31 Kim S, Hong JW, Cho W-D, et al. Characterization of two novel mAbs recognizing different epitopes on CD43. Immune Netw 2014;14:164-70.

32 Jeon YK, Min HS, Lee YJ, et al. Targeting of a developmentally regulated epitope of CD43 for the treatment of acute leukemia. Cancer Immunol Immunother 2011;60:1697-706.

33 Gillissen MA, de Jong G, Kedde M, et al. Patient-Derived antibody recognizes a unique CD43 epitope expressed on all $A M L$ and has antileukemia activity in mice. Blood Adv 2017;1:1551-64.

34 Bartels L, de Jong G, Gillissen MA, et al. A Chemo-enzymatically linked bispecific antibody Retargets T cells to a sialylated epitope on CD43 in acute myeloid leukemia. Cancer Res 2019;79:3372-82.

35 Flemming A. Trifunctional antibodies unleash NK cells. Nat Rev Cancer 2019;19:369. 